\title{
Entering Postgraduate Study: A Qualitative Study of a Neglected Transition
}

\author{
Jane Tobbell ${ }^{1}$, Victoria O’Donnell ${ }^{2}$ \\ University of Huddersfield ${ }^{1}$, University of West of Scotland ${ }^{2}$
}

\begin{abstract}
In this paper we demonstrate that whilst attention has been given to other educational transitions, the postgraduate experience has been largely ignored. We suggest this may be due to assumptions of expertise in that group. Here we consider literature together with data from a one year, multi-methods study into postgraduate transition. The literature and data suggest that postgraduate students lead complex lives and require targeted support to enable their study. The participants here did not position themselves as expert, confident learners but instead suffered a range of doubts surrounding their study skills and ability to manage the different aspects of their lives. University practices did not always support their struggles. We use communities of practice theory to understand the participatory transition trajectories. We end by acknowledging that this research represents a small percentage of postgraduate students in the particular context of the $U K$ and call for further research in different contexts to develop our understanding of postgraduate transition.
\end{abstract}

\section{Introduction}

In the UK in 2010/11, postgraduate students constituted $23 \%$ of the total number of students in higher education [1]. This represents almost a quarter of the total number, and therefore understanding the experiences of such students is crucial so that universities can better manage and facilitate their participation in the higher education community. Postgraduate students generate a significant income for higher education institutions (HEIs), and it is therefore in the interests of HEIs to support and engage such students, to facilitate their retention and to attract new postgraduates to their programs of study. Yet to date there has been very little research which has specifically focused on the transition to postgraduate study, although there are large bodies of research surrounding other educational transitions and transitions from education to work.
We have explored possible explanations for this silence in the literature in previous publications and have suggested that one explanation might be that postgraduate students are assumed to be more 'expert' than other students and that as a result their transitions are assumed to be less problematic and so less worthy of the academy's attention [2] [3]. If students' progress unproblematically from undergraduate to postgraduate study, then there would be little of interest to explore in this regard. Prior to this research we did not know if the transition was unproblematic because of the paucity of data but as a result of our experience of other educational transitions we hypothesized that there might be transition issues for postgraduate students upon entry. Having conducted this research, we would argue that the implicit discourse of unproblematic transition is not the case and within this paper we present some of the data from our one year ethnographic research project to support this claim. In addition, we explore the existing literature which explores postgraduate study, and argue that it does not support assumptions of expertise in postgraduate students, and instead, when approached holistically, reveals a complicated picture of postgraduate students' learning experiences.

\section{Postgraduate learning experiences}

Studies which have featured postgraduate students as participants do not support any supposition that such students are confident, independent learners which is the logical conclusion which emerges from the absence of literature and data surrounding the topic. Indeed research reveals shaky confidence and reticence in participation. Narrative research [4] carried out with a group of South African female doctoral students (all of whom might be presumed to be confident participants in academia as they were already higher education teaching professionals) found that the women felt unable to make facilitative learning relationships with their doctoral supervisors because of their perceptions of the power of those supervisors and their own relative lack of self-worth. This need for relationship and support has been identified in our own work [3] where many 
participants identified the need for personal support from university staff in the face of their struggles to engage with study. Students wanted identified, personal tutors to whom they could go when feeling overwhelmed, one student commenting:

'...I'm not the only one who is losing sleep and even feeling a bit tearful ...' (p271).

There is very little research which emphasizes relationship as a facilitator of learning in the higher education environment and it may be that the independent nature of academic practice underpins this lack of focus. However, relationship has been identified as important in other educational endeavors and it is not clear why this would cease to be the case on transition to higher education.

Other work has explored postgraduate student engagement with technology (an increasingly prominent part of university study) which has not been found to be a straightforward, linear process [5]. The findings report that postgraduate students who were part of an online masters module were very anxious about their online identity and were fearful about their contributions. The authors comment that:

'Issues of confidence, identity, self-presentation and social comparison clearly loomed large and were of paramount importance to these students' (p156).

Further research [6] reports that postgraduate students need to see the learning advantages of any technology and importantly, that they require specific support in order to fully engage. Falloon's work with postgraduates participating in a virtual classroom found that trust and rapport with other students were important and that in order to encourage engagement participants needed to identity with the group, any uncertainty resulted in withdrawal [7]. Once more the issue of relationship emerges, not just with the teacher but also with fellow students. This suggests that the experiences of students are distributed over the social context of the learning. Given this, transition research calls for ethnographic approaches which allow for contextual data.

This notion of identifying with the study community has also been identified as important in doctoral work. McCormack's study in Australia reveals that where students perceive a mismatch between their own study objectives and those of the university, in the form of institutional systems and supervisory practices, completion rates and timelines come under threat [8]. She found that whereas her participants thought of their study as an opportunity for relationship and personal development, the university view was more concerned with the economic imperatives of completion. This discontinuity between student - teacher and university imperatives represents one of the major challenges in considering transition. Where there is no meeting of minds in terms of basic goals in the study process it is difficult to see how successful transitions could be negotiated.

All of this previous literature therefore challenges the assumption that postgraduate students' learning experiences emerge unproblematically from their previous learning experiences, and suggests that instead such students experience uncertainty and a lack of confidence in engaging with postgraduate study. The view of HEIs of postgraduate students as competent, independent learners is not supported by the previous literature, and does not align with the views which postgraduate students have of themselves. Thus, the existing literature directly challenges the absence of postgraduate transition research in the academy. In fact, it would seem that notions of identity (in terms of individual understandings of research and learning and individual goals for undertaking learning) are paramount in understanding this final educational transition. It is to this issue of postgraduate student identity that we now turn our attention.

\section{Postgraduate student identity}

The mismatch between a university's ideas about postgraduate students' study versus the students' own constructions of postgraduate study underpin an important analytical point. Postgraduate students cannot be thought of as a homogenous group. O'Donnell et al. suggest that where there are institutional assumptions of homogeneity difficulties may arise [2]. This is particularly evident where skill in academic practice is assumed. Haggis [9] discusses the 'extreme diversity' (p216) of postgraduate students, pointing out that this diversity can be seen both in terms of their experiences of learning and in the 'technical aspects of study' such as writing or researching. In Humphery and McCarthy's questionnaire study, the heterogeneity of the postgraduate student body emerged and they argued that university social and academic provision should reflect this [10]. This echoes McCormack's claims discussed in the previous section where students revealed a variety of aims and understandings and these stood in contrast to the specific and sometimes unvarying aims of the institution.

Claims of heterogeneity in identity are important because they underpin a widening participation agenda. In recent years the UK has seen a massive expansion in undergraduate student numbers and it has been argued that this may lead to 'credential inflation' whereby the status of a Bachelor degree decreases, so the importance of a Masters or Doctorate increases [11]. This may lead to increasing uptake of postgraduate study and so an even wider heterogeneity in the student body. Such 
findings are commensurate with emerging evidence from undergraduate programmes and there is no reason to think that this will not be the case in future years in postgraduate study.

\section{Theorising postgraduate transition}

Available evidence highlights the importance of student identity in the postgraduate experience: identity surrounding engagement in learning and wider identity in the form of the life experiences students bring to their study. This seems to demand a theoretical understanding which foregrounds identity and suggests that learning is not a straightforward, linear process, but rather that it may be a more complex one which involves the whole person's engagement in tasks and activities, commensurate with the distributed notion of study argued for in the previous section. Communities of Practice theory takes just this approach $[12 ; 13]$. The ontological underpinnings of the theory argue that learning should be understood as participation in the valued practices of a given community and that the nature of the participation is determined by individual experience and the interaction of this with the practices of the community. As a result of engagement (or equally lack of engagement) the individual experiences identity shifts. This is illustrated by Falloon's research discussed above. Engagement in learning in the virtual classroom was not just a straightforward matter of going online and performing the tasks; rather it involved personal negotiation with the other members of the community in order to build relationships which would enable participation in the learning process. The relationships were perceived as an almost mandatory pre-determinant of learning, which is clearly, albeit implicitly, perceived in terms of participation. Given the diversity of the student body such negotiations would shift within and between student groups. In terms of practice, this would mean that effective learning strategies would need to enable the negotiation and formation of such relationships to promote participation. In the absence of this participation, learning might be undermined. Thus the practices of the community become a focus for research in understanding transition. Moreover, the extent to which those practices facilitate identity shifts which enable effective learning relationships to be established.

Lave and Wenger have suggested that initial participation in a new community can be thought of as 'legitimate peripheral participation', where newcomers are unfamiliar with the practices of the community but that this is accepted by all parties as 'legitimate' as a function of recent entry. Of course, peripherality becomes more problematic when participants also may fail to engage in the valued practices after an extended period of time and thus no longer have the protection of peripherality. Perhaps postgraduate students have not to date been conceptualised as peripheral participants in the higher education community as a result of their previous undergraduate success. Yet if the postgraduate learning community is characterised by practices which are unfamiliar to those who have previously been members of the undergraduate community, then it can be argued that undergraduate and postgraduate communities should be regarded as different, though overlapping, communities. As a result it would be incorrect to withdraw the protection of peripherality.

Peripheral participants must engage in the practices of a community in order to increase their participation and so strengthen their membership of the community [13]. Importantly, participation in the practices of a community needs to be learned from someone familiar with them, and engagement needs to increase in complexity over time. However, mere presence in the community does not guarantee positive participatory trajectories or moves from peripheral participation to full participation.

Wenger has identified several possible trajectories of participants entering a new community, all of which have concomitant impacts upon identity. These range from peripheral trajectories (where there is some identity shift, but problematic participation), to inbound trajectories (where participants join with a view to becoming full participants in future), to outbound trajectories (which result in the enablement of that individual in future communities of practice). In terms of postgraduate students, a peripheral trajectory may represent a student who feels unable to engage in the technological demands of the course and so comes to view themselves negatively. An inbound trajectory might represent a doctoral student who eventually wishes to pursue a career as an academic. An outbound trajectory may represent a doctoral student who is enabled by their studies to pursue a career in a related industry afterwards [12]. The nature of the postgraduate student in transition, their trajectory and their participation in the learning community therefore becomes a legitimate focus for research.

From the research evidence and theoretical understandings of learning explored here, three areas of research focus have emerged: firstly, the nature of the identities of postgraduate students; secondly, the nature of the practices which students must negotiate to participate in the learning community, and; thirdly, the emergent transition trajectories. This paper begins to explore these aspects of postgraduate study directly, and presents some initial findings. 


\section{Aims and methodology}

\subsection{Aims}

The aims of this research were:

- To explore the subjective identities of postgraduate students;

- To explore the practices of the community which construct postgraduate experience;

- To understand the participatory trajectories during transition.

\subsection{Methods}

The research was carried out over a one year period and included multiple methods. To address the above aims, we wished to collect data which reflected the subjective experience of postgraduate students, but also data which informed us of wider practices that constructed the postgraduate world, but of which students were not necessarily directly aware.

Students and staff from five UK universities participated in the research. In all 230 participants took part in this study:

- 44 students took part in one to one interviews and focus groups;

- 15 students completed email diaries over the year of study;

- 6 staff took part in one to one interviews;

- 180 staff and students were part of field observations;

- A range of university specific and wider policy documents were examined.

\subsection{Analytical process}

The data were analyzed using a constant comparative technique in which all transcripts, observation notes, diaries and documents were read and coded individually by at least two of the coinvestigators, each of whom sought to identify key emergent meanings. Comparisons were made between the different interpretations within and between the data, and within and between the researchers. The analysis took a focused problem approach, rather than an open problem approach [14] since the Communities of Practice framework within which the research was positioned informed the analysis as it took place. This allowed for a meeting of the incoming data and analysis with the existing body of literature.

\section{Analysis}

From the analysis, a number of key themes emerged. Three of these themes which specifically relate to the identified aims of this paper, are explored here in more detail. These are: Atypicality is typical; Assumed competence, and; Situating identity.

\subsection{Atypicality is typical}

Despite what may be implicitly held assumptions about the homogeneity of postgraduate students, in this study it was impossible to identify a 'typical' postgraduate student. The participants were involved in a range of programmes: some were research council funded and were engaged in full-time $\mathrm{PhD}$ study; some were self-funded and were engaged in part-time $\mathrm{PhD}$ study; some were funded by their employer who was supporting them towards parttime professional doctoral study; some were selffunded and undertaking full or part-time vocationally-focused taught Masters programmes; some were self-funded and undertaking research Masters programmes with little vocational element. These represent fairly superficial differences in terms of the types of courses being undertaken and the nature of students' funding. But it was equally difficult to identify any more subtle underpinning commonalities in terms of the characteristics of these students. For example, some participants had joined postgraduate study straight after their undergraduate degrees and were in their early twenties. Others had left university a few years previously and had been working in the interim, not necessarily in job roles related to their current or past studies, whilst some had left university many years previously and had had no engagement with formal education since then. Some had important, on-going professional responsibilities and their postgraduate study represented a significant part of their continuing professional development. Others had yet to identify a particular career path and were engaging in study in academic disciplines which interested and engaged them intellectually. Some students lived with partners and children and others were single and yet to start families. Some had come from other countries or cities whilst others were studying in their home towns, surrounded by established support systems. Some participants were employed in jobs associated with the university (part-time teaching for example), whilst others worked in unrelated employment such as restaurants or call centres to support their study.

The differences in their life experiences proved to be an influential part of their study experience. For example, those students who had families and children were constantly struggling with the demands necessary to manage family life, student 
life and sometimes work life as well. The following are quotes from interviews and email diaries:

'New domestic routine demands a bit more time with the children but less for study. Too many distractions for me to read during the day.'

'My partner's family disapprove of my studies, they think I should be working full-time. The resulting tension is difficult to endure.'

These quotes reveal the challenges faced by students attempting to engage in the practices of the postgraduate community, when their membership of other communities, and the valued practices of those other communities, differ significantly. Despite the large number of postgraduate students with family commitments, the inflexibility of the postgraduate community can prevent participation in its practices. Similarly, when a student's personal family community does not value the practices of formal education or of postgraduate education specifically, this represents a barrier to participation, and can affect the student's resultant trajectory.

Those without external funding for their studies were constantly juggling the need for financial support with the demands of study:

'I need to continue to work as a freelance trainer. This means that my studying is always affected by the level of work I have on. This past month has been very busy. This has affected my study life.'

The large proportion of self-funded postgraduate students in this study, and the low stipends available to those in receipt of external funding, should make it obvious that many postgraduates will need to be in some kind of paid employment alongside their studies. Yet the students experienced the postgraduate study environment as inflexible and often incompatible with their need to work. Whilst it was the case a number of years ago in UK universities that students were not required to work, as a result of government grants, this practice has not been in place for nearly two decades. Yet universities have not significantly changed their practices in response to wider macro policies within UK society.

The most important analytical point from this is that postgraduate students have complex lives which they cannot just put down and ignore in order to take up their studies. Very few of the participants in this research where unencumbered by family, financial or professional responsibilities and the management of these represent a significant challenge in transition. Yet nowhere in postgraduate programme policy or literature did we find reference to this, in even an oblique way. Wenger has commented that silences are as powerful as presences in understanding participation. HE institutions are largely silent regarding the external life demands of postgraduate students and as a result the students are left to themselves in negotiating what may be competing practices and identities.

\subsection{Assumed competence}

A pervasive theme from staff who participated in the research, and which emerged in lectures, tutorials and documentation, was the notion that students should be 'independent'. In fact it was difficult to know exactly what this meant. Independence might be understood to mean freedom of choice in how learning happens, what is learned and how that learning may be demonstrated [15]. In practice, it did not mean this because the content of the learning and the nature of assessments of that learning were imposed institutionally and were bound by traditional, valued academic practices, and in particular essays (or other pieces of extended writing). Students recognised that despite being postgraduates, they were not necessarily able to demonstrate these practices. For some students in this study, the academic discipline of their chosen postgraduate programme differed from the one they had studied as undergraduates (a further area of heterogeneity). They reported that the different requirements of different academic disciplines were not transparent to them, and that they struggled to 'perform' their knowledge in ways which were considered appropriate by staff. Other students indicated that the gap there had been between their undergraduate and postgraduate study, meant that the process of essay writing (in which they might once have been highly skilled) meant that they had forgotten how to successfully produce a good essay. Given that the art of essay writing is one which is valued only in educational contexts and not one which is regularly rehearsed in the outside world, it would not be reasonable to expect any students to have maintained this skill. Yet this was not addressed for them by staff, for whom assumptions of students' expertise in academic writing, prevailed. Independence also seemed to mean skilled. The data also demonstrated that the 'independence' which was expected of students by staff, was often understood by students as meaning that no direct help would be provided to them in respect of facilitating participation in such academic practices. The following quote is representative:

'There is perhaps an assumption that postgrad students know how to go about tackling essay questions. This is not necessarily the case. I would find it helpful to be given some guidance perhaps in the form of a separate lecture. The lecturer could run through some sample essay questions and explain how they would go about tackling the 
question. I don't mean in terms of essay content, but in the process they expect to go through in gathering information and formulating a response. What are some good techniques for taking information from articles? At what point do you construct the essay plan? Perhaps a seminar would be useful where students can share their methods with each other.'

As discussed above, an important part of the transition process is the shift from legitimate peripheral participation to more complex participation. This problem which students had in accessing support from staff to facilitate their negotiation of academic practice, undermined positive transition trajectories and sometimes resulted in resistance:

'The first week I thought I don't like this. I don't want to do it the way it's done ... I really felt I was in a foreign land.'

'Sessions are often too structured and there is not enough time for discussion. I'd be better off reading solidly for two hours on my own ... tutors say things like make it simple, write the right answer, but that doesn't fly with me, not on a Masters. It should be more than just regurgitation.'

'The first few months were just torture... I don't know but I think a lot of people drop out.'

The participants in this study were very clear that they needed support in their studies, but the nature of the support they sought varied between individuals. Those who had come straight from their undergraduate degree were more comfortable with electronic databases, online libraries and virtual learning environments; whilst older students returning to study after a significant gap still felt the urge to print or photocopy hard copies of journal articles or other resources in the library, and were wary of computers. Nearly all participants wanted support in writing their assessments. Very few of them expressed confidence in their academic writing skills. Postgraduate programmes, it seems, cannot assume advanced academic competence and need to support students towards becoming the kind of independent learners which the community values, in other words they must acknowledge the legitimacy of peripheral participation in postgraduate students. Indeed, a clearer articulation of what is meant by independent learning, and opportunities to learn the skills required to achieve this, would serve to provide access for postgraduate students, as peripheral participants in the community, to the practices which are valued and enacted by the 'experts'.

\subsection{Situating identity}

Wenger [12] explains the complexity of identity and argues that it is dynamic, it is constantly being constructed and reconstructed in the face of experience and defined '...with respect of the interaction of multiple convergent and divergent trajectories' (p154). It may be argued that at the point of and in the initial process of transition, identities are at their most vulnerable as a result of the problems of participating in new communities without knowledge of the rules of engagement. Students in this study described initial transition problems which might be expected, but more disturbingly, they also described on-going issues. The following quotes illustrate the kinds of issues which are still being encountered by students after more than nine months of postgraduate study:

'I'm hoping there's going to be a light bulb switched on somewhere, enlightenment.'

'And I've stressed over it for months and I can't see the jump to Masters and they say it's not about seeing, it's about feeling, you will feel it but I don't really ... I'm still trying to see where I've benefitted, I must have benefitted this year.'

'I've had a bit of a mental black. I do, I have a block and I do feel lower, I feel I could be helped with that. I guess it's for me to go out to get that help really... it's not as fun ... I don't feel as big really, as much as I have craved this course.'

These students' data clearly demonstrate that they have not assumed a coherent postgraduate identity and are troubled by their continuing feelings of peripherality. They are still uncomfortable with their studies and do not have a clear understanding of what is required or expected of them. A postgraduate identity is not an inevitable by-product of signing up for a programme of study. For those students who are unclear about what is expected of them, of what they are trying to achieve and of how they will achieve this, the learning process is problematic. There seems to be active, introspective engagement with change and where none is identified, feelings of confusion emerge and students may begin to question their legitimacy as postgraduates. The students' status as peripheral participants in the community has not shifted towards fuller participation, and this will have an effect upon the students' trajectories. A student who initially had an inbound trajectory and wished to pursue a career in academia, may shift their focus away from the community and be influenced instead towards an outbound trajectory. What might be of more concern to universities are students who do not continue with their studies at all as a result of this 
kind of challenge to their postgraduate identity formation, which might ultimately lead to poorer retention rates. Because postgraduate studies are not funded by government, there is less emphasis placed on retention at postgraduate level than at undergraduate level, where universities are given retention targets by central government. This therefore represents an important issue for universities, and a focus for future research might usefully explore how higher education institutions can help students to construct positive and enabling learning identities, to facilitate participation in the community.

\section{Discussion}

The aims of this paper, as identified previously, were threefold:

- To explore the subjective identities of postgraduate students;

- To explore the practices of the community which construct postgraduate experience, and;

- To understand the participatory trajectories during transition.

The students in this study presented very complex identities which were distributed over a number of, not always compatible, communities of practice. At times the different identities competed, reducing time and mental space for study. In general the practices of the universities did not account for this; indeed the universities were silent on this subject. Distributed, socio-cultural theories of learning argue that learning is not a contained event; instead it is a process which is influenced by a learner's past and present experiences and perhaps future aspirations. To overlook or to ignore the lives of students outside of the study context may not serve to enable learning.

From a university's point of view, perhaps what is more important is the fact that overlooking or ignoring the lives of students outside of the study context may adversely impact upon postgraduate student progression and retention. Moreover, it is a failure to acknowledge the shifting nature of study in the UK. As important sources of income, universities should usefully explore ways in which they can better accommodate the heterogeneity of postgraduate students through more flexible approaches to learning, teaching and assessment. Osborne [16] explored approaches to widening participation across six countries, and classified widening participation initiatives into three distinct groups. In-reach programs were those which focused upon attracting potential students to the institution. Out-reach programs were those which involved partnerships with outside organizations such as schools, employers and the community. But neither of these two approaches represented true systemic and structural re-organization to allow full participation. This, Osborne refers to as flexibility in program provision. At present, whilst universities are focused upon attracting postgraduate students to their institutions, the data presented here suggest that they are falling short of engaging in the kind of systemic and structural re-organization of their approaches to learning, teaching and assessment, which would allow full participation by those entering postgraduate study [2].

The data presented here highlight the notion of independent study as a particular source of concern in terms of participation and identity construction. It seemed that 'independence' was constructed by students as being left alone to struggle, rather than as having the freedom to think and develop learning in directions they might choose, or to engage in original and critical enquiry. Such practices, or perhaps lack of practices, undermine the establishment of positive, enabled transition trajectories. A number of students still felt lost after many months of study, seemingly craving relationships which would assist them in 'seeing the light'. It may be that independence cannot emerge without first experiencing collaboration. Future research might usefully focus on exploring university staff's implicitly and explicitly held conceptualizations of independent learning, with a view to uncovering how they might better support postgraduate students towards the practices of which such learning is comprised.

\section{Conclusion}

As we have stated, there is very little research which explores transition to postgraduate study and we are aware that participants in this research represent a minority of postgraduate students in the UK. However, the data presented here argue that the transition to postgraduate study is one which represents a significant shift for students in terms of learning, teaching and assessment practices, of identity and of trajectory. When viewed as a learning community which is 'different' to undergraduate study, the postgraduate environment should become a focus for research in itself. Communities of Practice theory has provided a useful theoretical lens through which to view this transition, the practices which constitute the postgraduate community and the identity shifts which accompany the transition. We hope that it may encourage others to explore this area and contribute more data so that our understanding of this important transition can develop and lead to a continuing amelioration of postgraduate student experience.

\section{References}

[1] Higher Education Statistics Agency (2012), http://www.hesa.ac.uk/ (2 October 2012). 
[2] V. L. O'Donnell, J. Tobbell, R. Lawthom and M. O'Neill (2009), 'Transition to postgraduate study: Practice, participation and the widening participation agenda', Active Learning in Higher Education 10(1), pp. 21-40.

[3] J. Tobbell, V.L. O'Donnell and M. Zammit (2010), 'Exploring transition to postgraduate study: shifting identities in interaction with communities, practice and participation', British Education Research Journal 36(2), pp. $261-278$.

[4] M.D. Magano (2011), 'Narratives on challenges of female black postgraduate students', Teaching in Higher Education 16(4), pp. 365-376.

[5] K. Littleton and D. Whitelock (2005), 'The negotiation and co-construction of meaning and understanding within a postgraduate online learning community', Learning , Media and Technology 30(2), pp. 147-164.

[6] Y. Blount and M. McNeill (2011), 'Fostering independent learning and engagement for postgraduate students: using a publisher supplied software programme', International Journal of Educational Management 25(4), pp. 390-404.

[7] G. Falloon (2011), 'Making the Connection: Moore's theory of transactional distance and its relevance to the use of a virtual classroom in postgraduate online teacher education', Journal of Research and Technology in Education 43(3), pp. 187-198.

[8] C. McCormack (2004) 'Tensions between student and institutional conceptions of postgraduate research', Studies in Higher Education 29(3), pp. 319-334.

[9] T. Haggis (2002), 'Exploring the 'Black Box' of Process: a comparison of theoretical notions of the 'adult learner' with accounts of postgraduate learning experience', Studies in Higher Education 27(2), pp. 208217.

[10] R. Humphery and P. McCarthy (1999), 'Recognising Difference: providing for postgraduate students', Studies in Higher Education 24(3), pp. 371 - 382.

[11] H.G. Van de Werfhorst, and J. Anderson (2005) 'Social background, credential inflation and educational strategies', Acta Sociologica 48(4), pp. 321-340.

[12] E. Wenger (1998), Communities of Practice, Cambridge University Press, Cambridge.

[13] J. Lave and E. Wenger (1991), Situated Learning: Legitimate Peripheral Participation, Cambridge University Press, Cambridge.

[14] G. Anderson (2002), Fundamentals of educational research, Routledge Falmer, London.
[15] G.M. Francom (2011), 'Involve Me and I Learn: providing substantial learning choices in higher education', American Educational Research Association Annual Meeting, New Orleans.

[16] M. Osborne (2003), 'Policy and practice in widening participation: A six country comparative study of access as flexibility", International Journal of Lifelong Education 22(1), pp. 43-58. 